This is Under CC BY SA Licence

\title{
KARAKTERISTIK PETANI DAN FAKTOR-FAKTOR YANG MEMPENGARUHI PRODUKSI BAWANG MERAH (Studi Kasus di Desa Senden Kecamatan Selo Kabupaten Boyolali)
}

\section{Farmers Characteristics and Factors Affecting Shallot Production (Case Study in Senden Village, Selo District, Boyolali Regency)}

\author{
Mahananto $^{1}$, Kusriani Prasetyowati ${ }^{1}$, Agung Prasetyo ${ }^{1 *}$ \\ ${ }^{1}$ Program Studi Agribisnis Fakultas Pertanian Universitas Tunas Pembangunan \\ Jl. Balekambang lor no.1 Manahan Surakarta \\ Email : Agungpras17@gmail.com
}

\begin{abstract}
Central Java was the largest shallot producing province in Indonesia with Boyolali Regency as one of the main producers. Selo sub-district was the main contributor to organic shallot production in Boyolali Regency. This study aimed to determine the characteristics of farmers who cultivate organic shallots and to determine the production factors that affect the yield of shallots in the Argoayuningtani Farmer Group. The data used in this research are primary data and secondary data. Sampling was done by using the census method and the data analysis method used was multiple linear regression analysis. The results showed that the respondent farmers were generally young people and had a good enough education to develop organic agriculture. Production factors in the form of labor and biological pesticides have a significant effect on the yield of shallots. Variables of seeds, manure, and the land area had no significant effect on onion production. Further guidance needs to be carried out and developed because generally, farmers who work and join farmer groups are young and educated farmers, making it easier to develop organic agriculture in Boyolali Regency. Training is needed to make organic fertilizers and biological pesticides with active microbial ingredients that have been tested to increase shallot production.
\end{abstract}

Keywords: Production Factors, Shallots, linear regression

\begin{abstract}
ABSTRAK
Provinsi Jawa Tengah merupakan provinsi penghasil bawang merah terbesar di Indonesia dengan Kabupaten Boyolali sebagai salah satu produsen utamanya. Kecamatan selo merupakan kontributor utama produksi bawang merah organik di Kabupaten Boyolali. penelitian bertujuan untuk mengetahui karakteristik petani yang berbudidaya bawang merah organik dan untuk mengetahui faktor-faktor produksi yang berpengaruh terhadap hasil produksi bawang merah di Kelompok Tani Argoayuningtani. Data yang digunakan dalam penelitian adalah data primer dan data sekunder. Pengambilan sampel dilakukan dengan metode sensus dan metode analisis data yang digunakan adalah analisis regresi linier berganda. Hasil penelitian menunjukan bahwa petani responden umunya merupakan anak-anak muda dan memiliki pendidikan yang cukup baik untuk mengembangkan pertanian organik. Faktor-faktor produksi berupa tenaga kerja dan Pestisida hayati berpengaruh nyata terhadap hasil produksi bawang merah. Variabel bibit, pupuk kandang dan luas lahan tidak berpengaruh nyata pada produksi bawang. Pembinaan lebih lanjut perlu dilakukan dan dikembangkan karena umumnya petani yang bekerja dan bergabung dalam kelompok tani merupakan petani usia muda dan berpendidikan sehingga memudahkan untuk mengembangkan pertanian organik di Kabupaten Boyolali. Perlu akan adanya pelatihan untuk membuat pupuk organik dan pestisida hayati yang berbahan aktif mikroba yang sudah teruji untuk meningkatkan produksi bawang merah.
\end{abstract}

Kata Kunci : Faktor Produksi, Bawang Merah, regresi linier 


\section{PENDAHULUAN}

Provinsi Jawa Tengah merupakan provinsi penghasil bawang merah terbesar di Indonesia pada tahun 2019 dengan jumlah produksi 48.890. Jawa Tengah sendiri tidak membuka jalur pemasaran impor Bawang Merah. tersebut dikarenkan produksi Bawang Merah dapat memenuhi permintaan konsumsi masyarakat. Salah satu produsen bawang merah di Provinsi Jawa Tengah adalah Kabupaten Boyolali dengan jumlah produksi 104,357 ton pada tahun 2019 (Badan Pusat Statistik Jawa Tengah, 2020). Kecamatan selo merupakan kontributor utama produksi bawang merah di Boyolali dengan luas panen $608 \mathrm{Ha}$ dan jumlah produksi 44,180 ton (Badan Pusat Statistik Kabupaten Boyolali, 2020).

Desa Senden merupakan salah satu bagian dari Kecamatan Selo yang memproduksi Bawang Merah. Di Desa tersebut terdapat 18 kelompok tani, dimana Kelompok Tani Argoayuningtani merupakan salah satu kelompok perkumpulan petani yang membudidayakan bawang merah. Pada tahun 2007 kelompok tani mendapatakan legalitas atas berdirinya kelompok tani dari Bupati Boyolali. Pada tahun 2013 Kelompok Tani Argoayuningtani menggarap sebagian tanah dan tanaman sayuran dengan cara organik salah satunya tanaman sayuran bawang merah, hal ini dikarenakan jika pengolahan terus menerus dilaksankan dengan konvensional maka semakin lama lahan yang digarap mengalami kerusakan. Menurut data produktivitas bawang merah tahun 2018-2019 Kelompok Tani Argoayuningtani Kecamatan Selo Kabupaten Boyolali masih berada di bawah rata-rata produktivitas nasional dengan jumlah perolehan sebesar 8,15 ton/Ha dan produktivitas nasional mencapai 9,33/Ha ton selama tahun 2018-2019.

Kendala teknis maupun kendala ekonomis menjadi hambatan proses pengusahaan bawang merah secara organik. Kendala ekonomis yang dimaksud adalah fluktuasi harga dan biaya produksi yang tinggi (Yuniarti dan Afsari, 2016). Akibatnya seringkali bawang merah diimpor karena lebih efisien dibandingkan dengan memproduksi bawang merah lokal yang masih relatif lebih tinggi biaya produksinya. Fluktuasi harga bawang merah sebenarnya dapat diatasi dengan melakukan penanaman bawang merah off-season (Purba, 2014) meskipun dalam prakteknya terkendala masalah teknis seperti penggunaan bibit yang berkualitas rendah, serangan OPT (organisme penggangu tanaman), dan teknik budi daya (Agung et al.,2020). Secara umum kendala yang dihadapi oleh petani bawang merah di Kelompok Tani Argoayuningtani Desa dalam usahatani adalah sempitnya lahan organik, kurangnya modal, rendahnya produktivitas, tenaga kerja, serangan hama dan penyakit pada tanaman. Kemampuan menggunakan faktor produksi yang terbatas dalam penentuan jumlah dan kombinasi yang tepat akan membantu mengurangi biaya produksi dan mendapatkan produksi yang optimal serta meningkatkan keuntungan petani. Permasalahan sempitnya lahan organik menjadi perhatian utama dengan penambahan luas lahan melalui konversi lahan semakin banyak dilakukan untuk anggota kelompok yang akan bergabung kedalam kelompok petani organik. Berdasarkan kondisi saat ini, penelitian yang dilakukan penting untuk mengetahui karakteristik petani yang berbudidaya bawang merah organik dan yang sedang melakukan konversi ke lahan pertanian organik. Penelitian ini juga bertujuan untuk mengetahui faktorfaktor produksi yang berpengaruh terhadap hasil produksi bawang merah di Kelompok Tani Argoayuningtani.

\section{METODE PENELITIAN}

Penelitian ini dilakukan di Kelompok Tani Argoayuningtani Desa Senden Kecamatan Selo Kabupaten Boyolali. Metode pengumpulan data dilakukan dengan empat cara yaitu observasi, wawancara, pencatatan dan kuesioner. Sampel yang digunakan dalam penelitian adalah 30 petani yang dipilih secara sengaja dengam pertimbangan sampel adalah petani yang membudidayakan bawang merah.Analisis penggunaan factor-faktor produksi yang berpengaruh terhadap hasil 
This is Under CC BY SA Licence

produksi pada usahatani bawang merah menggunakan fungsi produksi Cobb-Douglass dengan rumus sebagai berikut :

$$
\begin{aligned}
& \mathrm{Y}=\text { b0 } . X_{1} b^{1} \cdot X_{2}^{b^{2}} \cdot X_{3^{b^{3}}} \cdot X_{4}^{b^{4}} \cdot X_{5}^{b^{5}} \text {. e } \\
& \text { Keterangan : } \\
& \text { Y : Produksi bawang merah } \\
& (\mathrm{Kg}) \\
& \text { Bo : Intersep } \\
& \mathrm{X}_{1} \text { : Tenaga Kerja (HKO) } \\
& \text { (tenaga kerja wanita } 0,8 \\
& \text { tenaga kerja pria) } \\
& \mathrm{X}_{2} \quad \text { : Bibit }(\mathrm{Kg}) \\
& \mathrm{X}_{3} \text { : Pupuk Organik }(\mathrm{Kg}) \\
& \mathrm{X}_{4} \text { : Pestisida Nabati (Lt) } \\
& \mathrm{X}_{5} \text { : Luas Lahan } \\
& \text { b1-b5 : Koefisien regresi } \\
& \text { e : Error }
\end{aligned}
$$

Hubungan antara beberapa masukan yang berupa tenaga kerja, bibit, pupuk kandang, dan pestisida nabati yang digunakan pada usahatani bawang merah dapat diketahui dengan menggunakan analisis regresi linier berganda. Oleh karena itu, modifikasi dari fungsi produksi Cobb-Douglass harus diubah kedalam bentuk linier dengan cara dilogaritmakan menjadi:

$$
\begin{aligned}
& \mathrm{LnY}=\operatorname{Ln} \mathrm{a}+\mathrm{b} 1 \operatorname{Ln} \mathrm{X} 1+\mathrm{b} 2 \operatorname{Ln} \mathrm{X} 2+ \\
& \text { b3 Ln X3 - b4 Ln X4 + e }
\end{aligned}
$$

Selanjutnya untuk mengkaji apakah factor-faktor produksi yang digunakan secara bersama-sama berpengaruh terhadap produksi bawang merah digunakan uji $\mathrm{F}$ (F- test). Kemudian untuk mengetahui pengaruh factor produksi dari masing-masing (parsial) terhadap hasil produksi menggunakan Uji t (t- test).

\section{HASIL DAN PEMBAHASAN}

\section{Karakteristik petani sampel}

Identitas petani sampel merupakan gambaran umum mengenai keadaan dan latar belakang responden sebagai pelaku usahatani yang berpengaruh terhadap kegiatan usahataninya. Identitas petani sampel dalam penelitian ini meliputi umur, lama pendidikan, jumlah anggota kelaurga dan luas lahan garapan. Rata-rata umur petani sampel adalah
38 tahun dengan $90 \%$ sampel berusia dibawah 50 tahun. Petani sampel sebagian besar dalam golongan penduduk usia produktif dan relatif muda, hal ini dapat memberikan peluang kesuksesan lebih tinggi kepada petani karena dengan usia yang produktif dan lebih muda akan memiliki fisik dan tenaga yang lebih tinggi untuk menjalankan usaha tani. Usia yang relatif muda memberikan peluang untuk meningkatkan keterampilan dan memperluas pengetahuan mengelola usahatani bawang merah kearah yang lebih baik.

Tingkat pendidikan petani di kelompok Agroayuningtani dari SD hingga Diploma dengan rasio yang hampir berimbang antara petani yang berpendidikan rendah (SD, SMP) dan berpendidikan tinggi. Pendidikan akan berpengaruh pada sikap mental, penerapan inovasi baru dan perilaku bekerja saat berusahatani (Annisa et al., 2018). Semakin tiggi tingkat Pendidikan petani maka tingkat pengetahuan penerapan inovasi dan penggunaan teknologi baru lebih mudah dilakukan. Rata-rata jumlah anggota keluarga adalah empat orang. Petani responden merupakan penduduk asli yang telah lama berdomisili di Desa Senden dan pada umumnya merupakan petani yang sudah berkeluarga. Jumlah tanggungan keluarga adalah salah satu sumber yang menjadi pengeluaran kebutuhan sehari-hari petani. Semakin banyak jumlah tanggungan keluarga maka semakin banyak pula jumlah pengeluaran petani dalam kehidupan sehari-hari (Herien et al., 2019). Jumlah tanggungan keluarga akan mempengaruhi tingkat kerja petani. Apabila semakin banyak anggota keluarga maka petani harus semakin giat dalam bekerja untuk memenuhi kebutuhannya. Anggota keluarga juga tergolong tenaga kerja dalam keluarga yang dapat membantu kepala keluarga dalam usahatani. Rata-rata pengusahaan lahan di kelompok tani agroayuningtani adalah $1270 \mathrm{~m}^{2}$. Kepemilikan lahan yang sempit (kurang dari $0,5 \mathrm{Ha}$ ) menyebabkan pengelolaan usahatani menjadi tidak efisien sehingga produksi bawang merah yang diperoleh rendah.

\section{Hubungan Faktor-faktor Produksi dengan}




\section{JURNAL ILMIAH AGRINECA \\ ISSN : 2721-074X (Online) - 2301-6698 (Print) \\ Available on : http://ejournal.utp.ac.id/index.php/AFP/index \\ This is Under CC BY SA Licence}

\section{Hasil Produksi Bawang Merah}

hubungan antara umur petani, pendidikan, jumlah anggota keluarga dan luas lahan dalam usahatani bawang merah. Produksi dengan faktor- faktor yang digunakan pada usahatani bawang merah.
Faktor produksi yang dimaksud adalah tenaga kerja $\left(\mathrm{X}_{1}\right)$, bibit $\left(\mathrm{X}_{2}\right)$, pupuk organik $\left(\mathrm{X}_{3}\right)$, pestisida nabati $\left(\mathrm{X}_{4}\right)$ dan luas lahan $\left(\mathrm{X}_{5}\right)$. Jumlah koefisien regresi dari persamaan fungsi produksi bawang merah adalah sebagai berikut :

Tabel 1. Hasil Regresi Faktor yang Mempengaruhi Produksi Bawang Merah

\begin{tabular}{lcccc}
\hline \multicolumn{1}{c}{ Variable } & coefficient & Std. Error & t-Statistic & Prob. \\
\hline Ln X1 & $0,200^{*}$ & 0,312 & 0,336 & 0,031 \\
Ln X2 & $0,488 \mathrm{~ns}$ & 0,184 & 0,525 & 0,066 \\
Ln X3 & $0,446 \mathrm{~ns}$ & 0,308 & 0,433 & 0,560 \\
Ln X4 & $-0,007^{*}$ & 0,129 & 0,052 & 0,049 \\
Ln X5 & $0,303 \mathrm{~ns}$ & 0,232 & 4,743 & 0,061 \\
C & 0,432 & 2,211 & 0,195 & 0,342 \\
R-squared & & & & 0,916 \\
Adjusted R-squared & & & & 0,788 \\
F-statistic & & & & 13,326 \\
Prob (F-statistic) & & & & $0.000^{*}$ \\
Durbin-Watson stat & & & & 1.908 \\
\hline Sum
\end{tabular}

Sumber : Analisis data sekunder, 2020

keterangan: * signifikan pada tingkat kepercayaan 95\%, ns tidak signifikan

Berdasarkan tabel 1 diketahui nilai Adjusted R Square sebesar 0,788 artinya variasi perubahan produksi bawang merah dapat dijelaskan $78,8 \%$ oleh faktor produksi tenaga kerja, bibit, pupuk organik, pestisida nabati, dan luas lahan sedangkan sisanya $21,2 \%$ dijelaskan faktor lain diluar model penelitian ini seperti keadaan iklim/cuaca, sistem tanam, dll. Berdasarkan tabel diatas maka dapat diketahui bahwa nilai probabilitas F $(0,000)$ kurang dari 0,05 artinya faktor-faktor yang menjadi variabel dalam penelitian ini secara bersama-sama berpengaruh nyata terhadap produksi bawang merah.

Tenaga Kerja (X1) berdasarkan analisis uji t pada tabel 1 menunjukkan bahwa faktor tenaga kerja mempunyai nilai thitung 0,336 dengan probabilitas 0,031 kurang dari $\alpha(0,05)$ artinya tenaga kerja berpengaruh nyata terhadap produksi bawang merah. Nilai koefisien regresi bernilai positif sebesar 0,200 artinya setiap peningkatan $1 \%$ tenaga kerja yang dipakai maka akan meningkatkan jumlah produksi bawang merah sebesar $0,200 \%$. Dengan asumsi variabel lain dianggap konstan. Peningkatan tenaga kerja dalam pertanian organik sangat dimungkinkan. Pertanian organik mengehendaki tidak adanya proses kimia yang mengakibatkan kontaminasi dalam setiap produk yang dihasilkan sehingga proses kegiatan produksi hingga pemasaran lebih mengutamakan kegiatan manual dalam prosesnya. Proses manual dalam pertanian organik disusun dalam Good Agricultural Practices (GAP) (Suswadi et al., (2020), Tsurayya dan Kartika (2015)) dan Good Handling Practices (GHP) pertanian organik (Nurdi dan Baladina, 2017). Penggunaan proses produksi secara manual akan menyerap lebih banyak tenaga kerja, sehingga akan meningkatkan produksi. Temuan ini sesuai dengan temuan Susanti dan Hera (2017), yang meneliti faktor produksi bawang merah di Kecamatan Wanasari Kabupaten Brebes meskipun berbeda dalam konteks penelitian pertanian non organik.

Hasil analisis uji $\mathrm{t}$ pestisida (X4) menunjukkan nilai probabilitas $\mathrm{t}$ yang lebih kecil dari 0,05 artinya pestisida hayati berpengaruh nyata terhadap produksi bawang merah. Koefisien regresi pestisida hayati yang 
This is Under CC BY SA Licence

bernilai $-0,007$ diartikan bahwa setiap pertambahan $1 \%$ penggunaan pupuk hayati akan mengurangi resiko kehilangan hasil panen bawang merah sebesar $0,7 \%$. Pestisida hayati berpengaruh nyata pestisida membantu petani mengatasi kehilangan hasil produksi (loses) dikarenakan hama dan penyakit. Mikroba untuk pestisida hayati tanaman umumnya berasal dari jenis bakteri dan cendawan (seperti, Bacillus subtilis, Pseudomonas fluorescens, dan Trichoderma sp). Bakteri mengendalikan beberapa penyakit penting dan dapat mempertahankan produksi tanaman dan dapat menekan patogen hingga 30\% dan mempertahankan hasil panen 1,85\% dibanding pupuk dan pestisida, serta mengurangi penggunaan pupuk dan pestisida sintetik 50\% (Hanudin et al., 2018). Pestisida hayati juga mempunyai relung ekologi tersendiri yang spesifik, sehingga tidak berdampak negatif terhadap organisme bukan sasaran, termasuk musuh alami OPT (organisme pengganggu tanaman) atau organisme berguna lainnya, dan mencegah ledakan OPT sekunder (Bale et al. 2008). Aplikasi mikroba pengendali hayati lebih mudah, murah, dan efisien dibandingkan dengan pemupukan kimia dan pestisida sintetis (Hanudin et al. 2017). Dengan demikian, pengendalian hayati mampu mengurangi resiko kehilangan potensi produksi tanaman akibat OPT.

Hasil analisis uji t menunjukkan bahwa faktor bibit $\left(\mathrm{X}_{2}\right)$, pupuk kandang $\left(\mathrm{X}_{3}\right)$ dan luas lahan mempunyai nilai probabilitas lebih besar dari $\alpha(0,05)$ artinya bibit, pupuk kandang tidak berpengaruh nyata berpengaruh terhadap produksi bawang merah. Bibit akan menentukan jumlah produksi bawang merah. Bibit dengan potensi baik akan menghasilkan produksi yang tinggi sehingga produksi bawang merah juga akan tinggi. Bibit yang tahan hama dan penyakit tentu akan sangat menguntungkan petani (Kustiari, 2017). Di Kelompok Tani Agroayuning Tani penggunaan bibit merupakan hasil produksi sendiri dari hasil panen petani yang disimpan pada musim tanam sebelumnya. Bibit hasil simpanan sendiri tentu mempunyai ketergantungan kualitas dengan penyimpanan hasil panen yang sebelumnya dilakukan petani.
Penyimpanan yang dilakukan masih sederhana dengan menggantung dipara-para tetapi masih tetap efektif untuk menghasilkan bibit yang baik akan tetapi jika dibandingkan dengan bibit hibrida tentu potensi produksi bibit hasil simpanan petani masih kalah. Pupuk Organik (X4) juga tidak berpengaruh nyata terhadap produksi bawang merah di Kelompok Tani Agroayuningtani. Pupuk organik digunakan sebagai pupuk dasar kemudian dalam proses produksinya tidak digunakan sebagai pupuk susulan. Pupuk yang hanya diberikan satu kali pada setiap musim tanam ini diharapkan dapat memenuhi jumlah kebutuhan produksi pupuk organik bawang merah satu musim penuh meskipun secara sifat pupuk memungkinkan untuk diserap oleh tanaman pada satu musim tanam tetapi jumlah nutrisi hara pupuk organik sangat terbatas dan bergantung dari bahan komposisi pupuk. Kelompok tani menggunakan pupuk organik dari hasil limbah sayuran dan buah yang tidak layak jual. Pada material tersebut (limbah sayuran) kemungkinan besar terdapat mikroba patogenik dan nonpatogenik. Kedua mikroba tersebut dicampurkan dalam suatu tempat fermentasi. Mikroba nonpatogenik yang diharapkan dapat digunakan menjadi bahan aktif pupuk kemungkinan tidak kompatibel (kalah bersaing) dengan mikroba patogenik, sehingga pupuk organik yang dihasilkan membawa sumber penyakit bagi tanaman. Berdasarkan hasil uji t luas lahan tidak berpengaruh nyata terhadap produksi usaha tani bawang merah. Luas lahan akan mempengaruhi produktivitas. Semakin luas lahan akan meningkatkan produksi bawang merah yang dihasilkan petani. Lahan di Kelompok Tani Agroayuning tani rata-rata memiliki luas dibawah $1500 \mathrm{~m}^{2}$. Luas lahan yang sempit mengakibatkan produksi tidak dapat dihasilkan lebih banyak, apalagi dengan pertanian sistem pertanian organik kemungkinan untuk menambah luas lahan akan membutuhkan waktu yang lebih panjang. Penambahan luas lahan organik diwajibkan untuk melalui masa konversi lahan. Masa konversi lahan paling dipersyaratkan minimal dua tahun secara berturut-turut harus dibudidayakan dengan cara organik. Pada masa konversi tersebut produk bawang yang dihasilkan dari lahan belum 
dianggap sebagai bawang merah organik. Pengaruh luas lahan yang sempit dan adanya proses yang harus dilalui untuk dianggap sebagai lahan pertanian organik mengakibatkan luas lahan tidak berpengaruh nyata terhadap produksi bawang merah petani.

Hasil uji asumsi klasik pada uji normalitas menunjukan bahwa data terdistribusi normal. Uji multikolinearitas dengan menggunakan nilai VIF (Variance Inflation Factor) menunjukan nilai VIF berada direntang 0,0231 dan 5,3241 yang menunjukan angka dibawah 10. Uji tersebut menunjukan tidak terdapatnya multikolinearitas dalam model. Nilai durbin Watson menunjukan pada tabel satu juga menunjukan tidak terdapat autokorelasi dan melihat pola titik-titik pada grafik scatterplot menunjukan bahwa data tidak terdapat heteroskesdatisitas.

\section{KESIMPULAN}

Berdasarkan hasil penelitian usahatani bawang merah yang ada pada KelompokTani Argoayuningtani di Desa Senden Kecamatan Selo Kabupaten Boyolali Tahun 2020 dapat disimpulkan bahwa karakter petani responden umunya merupakan anak-anak muda dan memiliki pendidikan yang cukup baik untuk mengembangkan pertanian organik. Faktorfaktor produksi berupa tenaga kerja (X1) dan Pestisida hayati berpengaruh nyata terhadap hasil produksi bawang merah. Variabel bibit, pupuk kandang dan luas lahan tidak berpengaruh nyata pada produksi bawang. Penggunaan faktor produksi bawang merah perlu dioptimalkan agar menghasilkan produk bawang merah yang lebih baik secara kuantitas. Pembinaan lebih lanjut perlu dilakukan dan dikembangkan karena umumnya petani yang bekerja dan bergabung dalam kelompok tani merupakan petani usia muda dan berpendidikan sehingga memudahkan untuk mengembangkan pertanian organik di Kabupaten Boyolali. Perlu akan adanya pelatihan untuk membuat pupuk organik dan pestisida hayati yang berbahan aktif mikroba yang sudah teruji oleh kementrian pertanian dan BNSP agar petani dapat membuat pupuk organik yang dihasilkan lebih terjamin dari mikroba patogen penyakit bawang merah sehingga menjamin produksi petani yang lebih baik.

\section{DAFTAR PUSTAKA}

Agung BS, Maryam N, Ismatul H. 2020. Daya Saing Bawang Merah di Provinsi Maluku dan Upaya Peningkatannya. Jurnal Ilmu Pertanian Indonesia Juli 2020 Vol. 25 (3): 365-372. DOI: 10.18343/jipi.25.3.365

Annisa I, Ratna WS, dan Rita N. 2018. Efisiensi Pemasaran Bawang Merah (Kasus: Kabupaten Brebes, Provinsi Jawa Tengah). MIX: Jurnal Ilmiah Manajemen, Volume 8, No. 2, Juni 2018. DOI: dx.doi.org/10.22441/mix.2018.v8i2.005

Badan Pusat Statistik [BPS]. 2018. Boyolali Dalam Angka. Boyolali (ID): Badan Pusat Statistik.

Badan Pusat Statistik [BPS]. 2020. Luas Panen dan Produksi Bawang Merah, 2017-2019. Semarang (ID): Badan Pusat Statistik.

Herien P, Yasmin A, Aditya M, Azmi FR. 2019. Relasi Gender, Ketahanan Keluarga Dan Kualitas Pernikahan Pada Keluarga Nelayan Dan Buruh Tani "Brondol” Bawang Merah. Jur. Ilm. Kel. \& Kons., Januari 2019, Vol. 12, No.1 p $1-12$. DOI: http://dx.doi.org/10.24156/jikk.2019.12.1.1

Kustiari, R. 2017. Perilaku Harga Dan Integrasi Pasar Bawang Merah Di Indonesia. Jurnal Agro Ekonomi, Vol. 35 No. 2, Oktober 2017:77-87 DOI:

http://dx.doi.org/10.21082/jae.v35n2.2017.77-87

Nurdi M, Baladina N. 2017. Analisis Keunggulan Komparatif Usaha tani Bawang Merah di Desa Ponjanan Barat, Kecamatan Batumarmar, Kabupaten Pamekasan. Jurnal Ekonomi Pertanian dan Agribisnis. I(1): 44-55. https://doi.org/10.21776/ub.jepa.2017.001.01.5

Purba R. 2014. Produksi dan Keuntungan Usaha tani Empat Varietas Bawang Merah di Luar Musim (OffSeason) Dikabupaten Serang, Banten. Jurnal Sosial Ekonomi Dan Kebijakan Pertanian. 3(1): 55-64.

https://doi.org/10.21107/agriekonomika.v3i1.44 0

Susanti, Hera. 2017. Analisis Pengaruh FaktorFaktor Produksi Terhadap Produksi Usahatani 


\section{AGRINIECA}

JURNAL ILMIAH AGRINECA

ISSN : 2721-074X (Online) - 2301-6698 (Print)

Available on : http://ejournal.utp.ac.id/index.php/AFP/index

This is Under CC BY SA Licence

Bawang Merah Di Kecamatan Wanasari Kabupaten Brebes. thesis, Program Studi Agribisnis Departement Pertanian. Universitas Diponegoro.

Suswadi, Agung Prasetyo, K Sutarno, Prasetyowati, Mahananto, Mth Handayani. 2020. Analysis of Youth Farmer Involvement in the Application of Good Agricultural Practices (GAP) of Organic Rice. TEST Engineering and Management vol 83 (2020) 7267 - 7271 .
Yuniarti AR, Afsari MD. 2016. Profil Komoditas Barang Kebutuhan Pokok dan Barang PentingBawang Merah. Jakarta (ID): Kemendag.

Tsurayya S, Kartika L. 2015. Kelembagaan dan Strategi Peningkatan Daya Saing Komoditas Cabai Kabupaten Garut. Jurnal Manajemen dan Agribisnis. $12(1)$ : 1-12. https://doi.org/10.17358/

JMA.12.1.1 